\title{
THE DISCOURSE OF COSMETIC SURGEONS AS THERAPISTS IN A PRIVATE MEDICAL MARKET: SOCIAL MEDIA REPRESENTATIONS
}

\author{
Carmen VOINEA ${ }^{a^{*}}$ \\ ${ }^{a}$ University of Bucharest, Romania
}

\begin{abstract}
Drawing on thematic content analysis, this paper explores the legitimation repertoires employed by Romanian cosmetic surgeons in their in social media (Instagram) discourse. I argue that the main themes they use derive from their legitimation as psychotherapists operating for the well-being of their patients, and from their position of private medical services providers. Firstly, as surgeons need to reconcile their medical profession with the profit motive, their social media representations consist of their being shown in the avant-garde of progress as medical, and technical innovators. Their representation as innovators is legitimated as ultimately being beneficial for the patients' surgical transformation. Secondly, their legitimation of the surgical interventions on healthy bodies draws its foundation from the psychological domain. The cosmetic surgery interventions are presented as being performed for the psychological well-being of the patient. Another dynamic that underlies this process is the pathologization of women's bodies, in which traditionally surgeons play an important role on account of their power derived from their scientific authority. Lastly, in the context of a neoliberal consumer society, women have become informed-patient consumers. This development informs the legitimation repertoires of surgeons who willingly share their expertise with their patients. Consequently, their social media posts consist of content in which they aim to educate their audience by sharing various medical and technical aspects.
\end{abstract}

KEYWORDS: cosmetic surgery, informed patient-consumer, legitimation repertoires, psychology, social media representations.

\section{DOI: 10.24818/IMC/2021/05.07}

\section{INTRODUCTION}

Since the dawn of modern cosmetic surgery, surgeons have struggled with the challenging task of legitimating their interventions. As the medical specialty grew in respectability, benefiting from professionalization, the expansion of consumer society, and the legitimating force brought by psychology, the legitimation repertoires of cosmetic surgeons also diversified and integrated ever more subtle repertoires of justification. However, several challenges and corresponding legitimation needs remained rather constant over space and time. Following my doctoral thesis The social practice of cosmetic surgery in Romania. Embodied self-development, the gaze of others, and legitimation repertoires (Voinea, 2020), in this paper I aim to explore two main areas of legitimation identified among Romanian cosmetic surgeons in social media. They revolve around their role as psychotherapists and of private medical service providers, in the context of the constant privatization of this medical specialty that characterised cosmetic surgery since the fall of the socialist regime and especially in the last decade (Voinea, 2020). Although the focus of this paper is set on doctors, I will outline their intricate relationships with their patients - women who are

\footnotetext{
* Corresponding author. E-mail address: carmen.giorgiana.voinea@gmail.com
} 
involved in this gendered practice as informed patient-consumers in a quest for embodied selfdevelopment (Voinea, 2020).

I decided to focus on one social media platform (Instagram), because as a highly visual medium, it is a privileged and preferred site for both surgeons, and their clients. It can be seen as a medium where beauty standards are produced, circulated, and internalized; where the pathologization of women's bodies finds a fertile ground, where filters applied to photos already announce the growing involvement of women in their own physical modification, while the narratives of embodied self-development that accompany the Before and After photos cement the link between physical and psychological evolution and the imperative of working on one's embodied self; where cosmetic surgeries are normalized and the normalization of women's bodies can best be observed. Moreover, it is also the locus where women seek information about surgeries, clinics, prices, and accounts of surgical transformation, while the surgeons promote their business, the new cutting edge technologies, but also where they legitimate the surgical interventions, and help nurture the growing needs for these practices.

Regarding the theoretical framework of this paper, it has its roots in several traditions such as feminism, phenomenology, communication studies, and it marginally intersects with sociology of professions.

The exploration into the discourse of Romanian cosmetic surgeons as they are constantly legitimating their practice was carried out by employing thematic content analysis applied to their social media pages. I believe this is a well suited methodological approach for identifying the two main themes outlined previously: that of the surgeon acting as a psychotherapist, operating for the physical and psychological well-being of their patients, and that of a private medical service provider in a neoliberal capitalist frame. In the analysis, I used open coding and opted to divide it into two main categories. More traditional mass-media, especially television, has long been researched in relation to its impact on the spread of cosmetic surgery. Scholars like Sue Tait (2007), Meredith Jones (2008a, 2008b), Heyes (2007), Elfving-Hwang (2013) have taken a critical stance on mass-media and the normalization of these invasive bodily modifications. A special mention should be made regarding Sue Tait's concept of "domestication of cosmetic surgery" (2007) through television, and in particular makeover shows. With the advent of social media in the last decades, similar focus should therefore be given to this new medium and its productive role in the social practice of cosmetic surgery.

\section{SOCIAL MEDIA REPRESENTATIONS OF COSMETIC SURGERY}

\subsection{The pathologization of women's bodies}

Although the focus of this paper is the legitimation repertoires of cosmetic surgeons in social media, we cannot fully understand their position without laying out several characteristics of how the other actors involved in this practice come to submit themselves to these invasive interventions. Feminist literature about cosmetic surgery has, since as early as 1970's, formulated a critical stance regarding the patriarchal pressures for the normalization of women's bodies, sometimes viewed as mutilation, driven by the surgeons as they rely on the authority of scientific rationality (Kaw, 1993). The concept of normalization is used here in Foucauldian tradition, following Cressida J. Heyes as she described it as a "process of defining a population in relation to its conformity or deviance from a norm, while simultaneously generating narratives of individual authenticity" (2007, p. 17). Most feminist scholars reached a consensus that revolves around the fact that women's healthy bodies have been pathologized. Consequently, among others, Naomi Wolf argues that "cosmetic surgery processes the bodies of woman-made women, who make up the vast majority of its patient pool, into man-made women" ([1991] 2002, p. 220) instrumented by the male surgeons. Furthermore, she contends that by the hands of the surgeons driven by their own profit motives, "cosmetic surgery 
industry is expanding by manipulating ideas of health and sickness" ([1991] 2002, p. 220). Viewing women's bodies as pathological became so pervasive that, according to Shelley Budgeon (2003), women came to develop a strange strategy to come to terms with it. For her, the pathologization itself was normalized for all women, as "the discomfort produced by their desire for what they did not have was dissolved by placing all women within this position" $(2003, \mathrm{p}$. 44). This is similar to what has been observed by numerous other scholars, the fact that women are more associated with their bodies, therefore it is expected from them to take more care of their bodies, including by subjecting themselves to painful procedures, such as invasive cosmetic procedures. Shelley Budgeon synthesises this by arguing that women "have always been more embodied than men because of the association of the feminine with the body" (2003, p. 38).

As I argued in my doctoral thesis, the surgical gaze contributes significantly to women viewing themselves as in need of restoring their bodies to a normal state, by correcting the alleged body defect, while legitimating the change based on the need for constant self-development at both physical and psychological level (Voinea, 2020). Furthermore, what Meredith Jones keenly observed for makeover television, the fact that cosmetic surgery recipients will ultimately internalise the medical gaze and even "become their own "surgeons", which will help to "encourage ordinary people to see their bodies as deficient" (2008b, p. 68), is also valid for social media.

\subsection{The emergence of informed patient-consumers}

I have claimed that women, as patients and clients of cosmetic surgery, see their bodies as abnormal and this is inextricably linked to the role of the surgeons (even medicine in general) and their surgical gaze that women internalize. One simultaneous development is also important in order to detail how their subjective experiences are linked to the macro level, in which neoliberalism, and the privatization of plastic surgery fundamentally alters even the role of a patient (Voinea, 2020). In a consumer society, I argue that women become informed patient-consumers as they borrow "from the private market ways of relating to their status as patients" and they see themselves more as consumers than just patients (Voinea, 2020, p. 65). Meredith Jones observed a similar dynamic that also changed the relationship between patient and surgeon. For her, the patients "are no longer dependent on surgeons for information and expertise" (2009, p. 176), and this also entails new strategies from the surgeons who have to take on new roles, inspired by the same market dynamic, while they also allow a partial decrease in authority. This can be seen especially in the preparation process for the surgery, where women take on an active role of gathering information about the surgery, including minute details about medical procedures and devices used, they schedule consultations with multiple surgeons, and in this process they become informed patient-consumers, and more self-knowledgeable agents (Voinea, 2020).

Compared to the pathologization tendency previously described, this consumer market dynamic brings an interesting development that Meredith Jones (2008b) aptly observes: in order to succeed in attracting clientèle, the recipients should not be viewed as sick, and "cosmetic surgery must not stigmatize its buyers" (2008b, p. 68). Therefore, she goes on to argue that the procedures need to be presented as "psychologically necessary," with doctors having to not "bully women into having cosmetic surgery, they must now sell the procedures to discerning and knowledgeable clients" (2008b, p. 68). She also further argues that the patient-consumer that is "increasingly critical and knowledgeable" competes with the doctor who once held a strong authority, a state that, according to her, although mourned by the surgeons also has its benefits as the doctors recognize "that stronger patient knowledge and wider dissemination of information about cosmetic surgery equals more business and larger profits" (2009, p. 185). 


\subsection{Surgeons: psychotherapists operating for the well-being of the patients}

Departing from simply presenting their patients as deficient or sick, as Meredith Jones indicated, surgeons employ a key legitimation repertoire: that of their role in the psychological improvement of their patients. Sander Gilman who brought an important contribution to the social history of cosmetic surgery stressed in his works the pivotal role psychology had in shaping this medical specialty. His book insightfully titled Creating beauty to cure the soul. Race and psychology in the shaping of aesthetic surgery (1998) synthesises the legitimating force the arguments borrowed from psychology had for this medical branch and its practitioners. He argues that in USA, in the first half of the twentieth century, concepts like "inferiority complex" inspired by Alfred Adler marked a turning point for legitimating operations on healthy bodies (1999), at a time when the new medical specialty was struggling with accusations of quackery, of lack of professional rigour, or breaking the Hippocratic Oath (Haiken, 1997). As I have showed in my research regarding the consolidation of the social practice of cosmetic surgery in Romania, surgeons face similar issues of legitimation (Voinea, 2020), and this supports the need for ongoing inquiry into the legitimation repertoires employed by the medical practitioners of this industry. Gilman's key thesis is that "aesthetic surgery is a form of psychotherapy" (1998, p. xi), and that its expansion from Western Europe and United States can be linked to the spread of psychoanalysis (1998, p. 19).

The influence of the "psy" sciences on the development of individuals in the liberal democracies of the Western World is analysed by Nikolas Rose (1996) who inspired several scholars' inquiries into the social world of plastic surgery. The "psy" sciences successfully managed to center individuals' development around key concepts like personal responsibility and choice. It is also striking that these tropes permeate the accounts of both surgeons and patients in present day Romania in their quest to justify their actions and recount their experiences (Voinea, 2020). Susan Fraser showed how psychology helped to portray this medical specialty "as therapeutic and therefore medically valid" (2003, p. 78). The potential for justification or legitimation that psychology has is brought forward by Rose who considers it a "generous discipline" as it offers "psychological vocabularies" to various "agents of social authority" in order to explain "normality and pathology in psychological term" (1996, p. 87). However, he considers that at the same time that the individuals come to rely on "the powers of expertise" (Rose, 1996, p. 160), they are also required to become responsible and to obtain "self-knowledge and self-mastery" (Rose, 1996, p. 157).

This interplay between psychologically inspired tropes of individual freedom, responsibility, the imperative for self-knowledge, and self-development on one side, and the need to rely on the authority of the experts (doctors) whose powers of justification are based on the same psychological vocabularies, is telling of the complex dynamic between surgeon and informed patient-consumer. This is a dynamic that is embedded in the psychological domain, but one that also has to operate in a consumer capitalist market that further adds another layer of complexity. Therefore justifications in psychological terms are intertwined with legitimizations in market specific notions. The surgeons are operating for the well-being of the patient, however they are also profit driven, and these are the two main themes that I aim to unearth in the social media representations of cosmetic surgeons' discourse.

\subsection{Surgeons in the avant-garde of business and medicine}

As medical practitioners who are active in a private market, surgeons often need to reconcile their medical profession with the profit motive. I therefore argue that the authority of their medical expertise (often represented in social media with images or videos from operating rooms) is strongly intertwined in manifest and latent ways with that of private medical service providers. The more conspicuous representations can be identified in their promotion of services rendered, classic marketing strategies, depictions of their business ventures that indicate an almost complete integration of the economic logic in their medical profession. The more subtle ones, that are subsumed to their medical expertise, are those that present them in the avant-garde of progress by 
means of innovations that some of them are themselves architects of. This is based on the assumption, one that will not be further developed here, that innovation is seen as of tantamount importance for the development of capital. The constant social media representations of this theme by some cosmetic surgeons testifies to the high importance they place on this aspect for their business development and the legitimation of their dual position of both medical experts and technical innovators. Therefore, surgeons as innovators not only develop new medical techniques to be competitive in the cosmetic surgery industry, but increasingly do so by relying on and developing new digital tools or medical devices.

It is also worth mentioning that some of these tools allow and even encourage the informed patientconsumer to be more involved in her own bodily change. As Gilman argued, the resemblance between cosmetic surgery and psychoanalysis is also visible in that the patient can propose a course of treatment (1998, p. 14). Therefore, involving the patient in her own improvement, a dynamic that shows how the patient-consumer is practically made more responsible in this process, is mediated by innovative technologies. A telling example comes from the Instagram page of doctor Constantin Stan where he advertises a breast implant and a medical technique, as well as a more recent Augmented Reality application through which the patient can make her own simulation of the desired breast shape (Stan, 2020). Only after the simulation is sent via e-mail to the surgeon, the patient is invited to schedule a consultation. As discussed in previous research, what this post also "points to is a transformation of the medical act itself," as "the surgeon willingly becomes a promoter and creator of new technologies and willingly declines part of his medical authority to non-human objects" (Voinea, 2020, p. 75). Consequently "this alliance to new technologies" can be seen as having a legitimating effect especially since "being on the avant-garde of science increased their authority as experts in the past as well, and legitimated their claims to authority" (Voinea, 2020, p. 75).
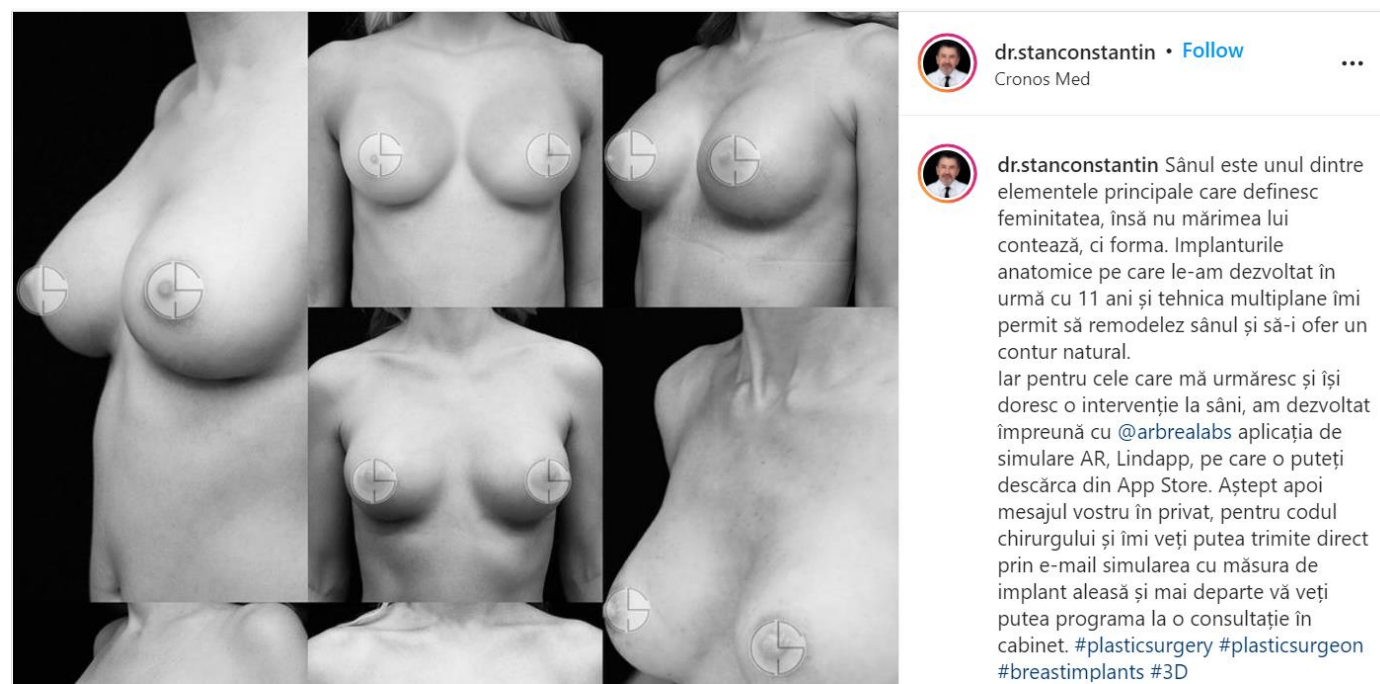

Figure 1. Breasts, implants, and applications for their modification Source: Stan (2020).

Following the captivating proposal of Meredith Jones (2008b) of looking at cosmetic surgery through the theoretical lens of actor-network theory, the presence of such objects (implants, digital tools etc) in cosmetic surgeons' social media posts opens new lines of inquiry: that of seeing the cosmetic surgery phenomenon beyond the two main actors (patient and surgeon). The social media discourse is therefore populated by objects, as well as humans, where the latter are found in intricate relationships of power, embedded in various vocabularies (psychology, economy etc.), all involved in social reproduction. The complex reality can therefore be understood in terms of networks that bring together human and non-human entities, or in terms of hybrids in Bruno Latour's (1993) genealogy. 


\subsection{Social media representations of two surgeons legitimation repertoires}

In the analysis of the social media representations of the two main themes of legitimation cosmetic surgeons employ, after a careful consideration of several other online profiles of cosmetic surgeons and clinics, I decided to select the Instagram accounts of two well known Romanian cosmetic surgeons. I chose the two surgeons as, at a first glance, they have very different online brands and apparently different ways of employing legitimation repertoires. However, after a more in depth thematic content analysis of their social media profiles we can trace common justifications repertoires, albeit some are more poignant in one case than the other. One surgeon is doctor Constantin Stan, one of the pioneers of the private cosmetic surgery industry in Romania after the fall of the socialist regime. His career is contemporary with the dawn of Romanian cosmetic surgery in its evolution to today's characteristics. His Instagram account focuses on legitimation repertoires that revolve around his medical expertise, and technical innovations, as well as the celebration of his successful business model. The majority of the posts represent scenes from the operating room, photos from medical conferences, testimonials of satisfied patients, and new products, especially related to cutting-edge digital technology for body modification.

The other doctor is surgeon Radu Ionescu, who belongs to a more recent generation of Romanian surgeons. He is specialized in breast surgery and his Instagram account has a more informal approach to his representation as a surgeon, especially as he blends together personal photos from family vacations, with professional ones from the operating rooms, or from conferences. In his profile he is often photographed alongside celebrity patients, indicative to a business model that includes "barter," a practice where a surgeon offers a procedure for free to a celebrity or an "influencer," in exchange for being promoted in social media. Furthermore, he associates his business model with luxury products. A special category of posts consists of memes about cosmetic surgery, its recipients, and the surgeons performing them. I use the following definition of memes: "small pieces of content that are mundanely passed around by Internet users" (Nissenbaum \& Shifman, 2018).

A common theme of both surgeons is their reliance on the legitimation power of the psychological argument, the fact that their interventions follow the purpose of helping women in their process of self-development. Therefore, both of them mention the happiness of women as their main goal. In an Instagram post, doctor Radu Ionescu aims to depart from the claim that cosmetic surgeons cater to women's vanity of simply being beautiful, and he posits as his recurrent professional motto that of making women happy (Ionescu, 2019).

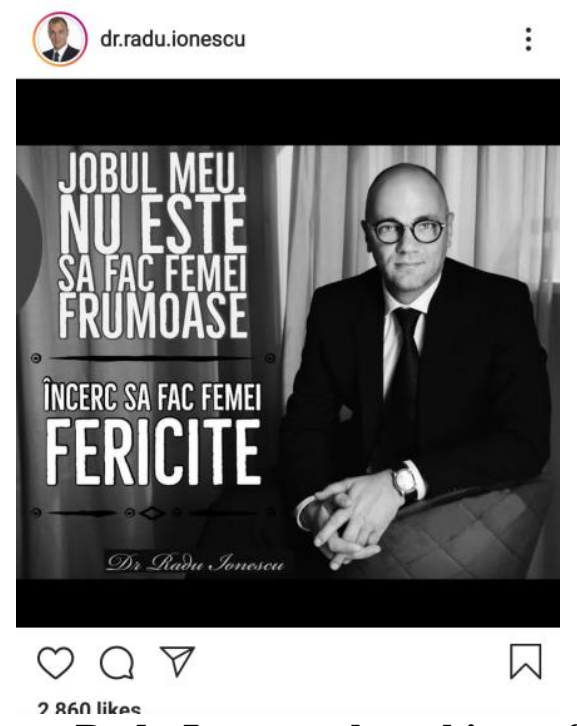

Figure 2. Doctor Radu Ionescu about his professional goal Source: Ionescu (2019). 
The pivotal role of psychological vocabulary in legitimating the surgical interventions are epitomised in doctor Constantin Stan's Instagram page, as well as on the account of his clinic Cronos Med, by a series of weekly posts with the title "The Psychotherapy Pill." They consist of videos in which a psychotherapist employed by the clinic tackles various topics pertaining to psychological well being. Furthermore, the inextricable link between psychotherapy and surgical transformation is present in various other posts, for example, promoting topics about beauty and "what really makes us happy" (Stan, 2021b).

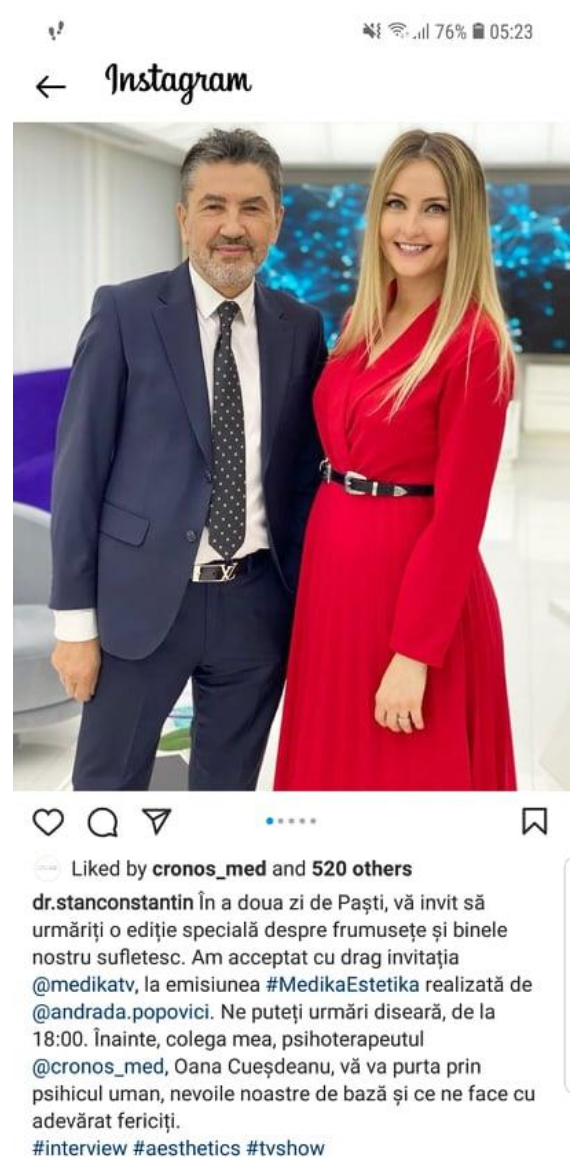

Figure 3. Dr. Stan takes part in a TV show where he speaks about beauty and happiness Source: Stan (2021b).

Another special category of Instagram posts, that causally links the benefits of the surgical change to the psychological development of women, are the testimonials of happy clients. 


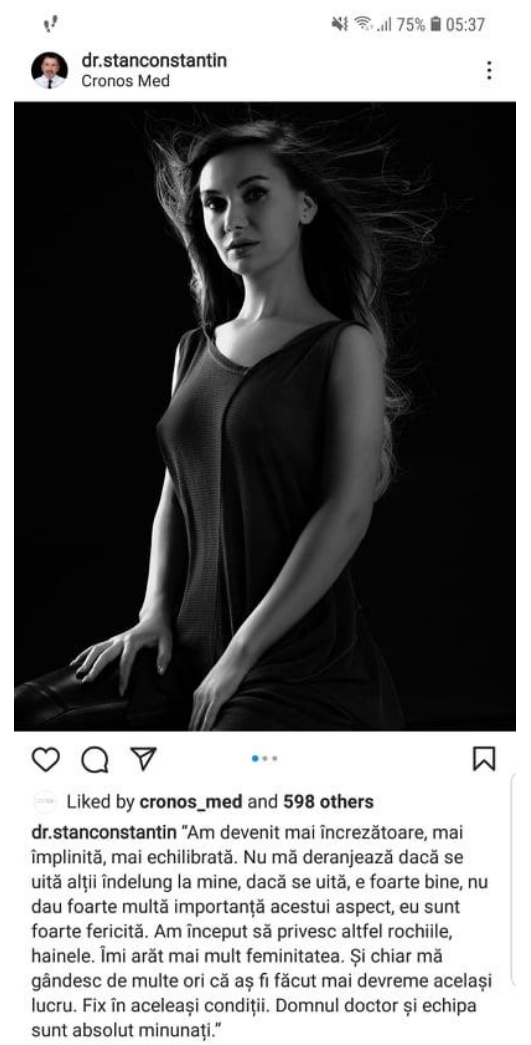

Figure 4. Dr. Stan Instagram Testimonial of satisfied patients

Source: Stan (2021d).

If most of doctor Stan's patients on social media are regular people, doctor Ionescu chooses to promote almost exclusively celebrities or influencers.

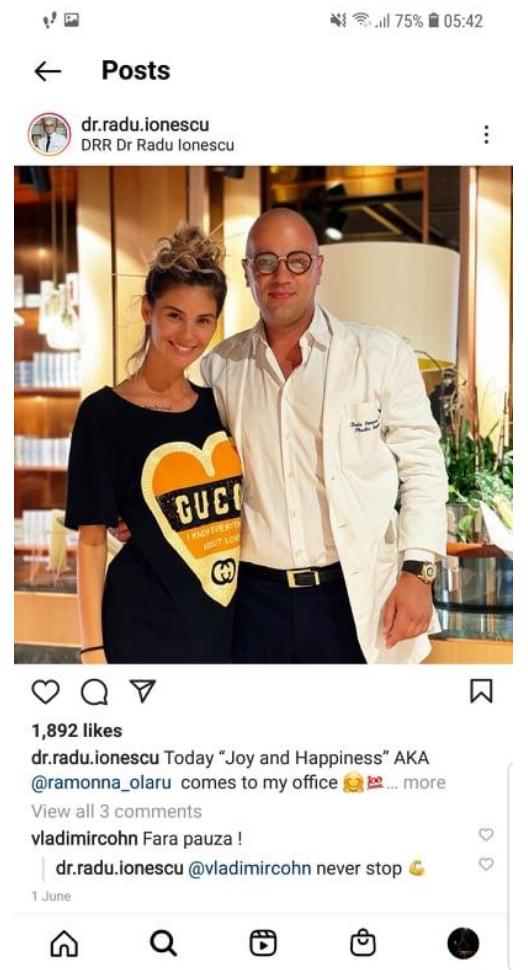

Figure 5. Dr. Ionescu Instagram Testimonial of a satisfied patient Source: Ionescu (2021d). 
I have argued previously that the private market dynamic, that informs cosmetic surgeons' legitimation repertoires, relies also on the emergence of the informed patient-consumer, towards which the doctor willingly shares his expertise. Therefore, many of the social media posts present to the audience videos from the operating room, during which the surgeon details the procedure with the declared goal of educating the clientèle, and informing it about "each step [of the operation] until the final result." (Stan, 2021c) This can also be viewed as a way through which the informed patient-consumer can experience the surgical gaze.

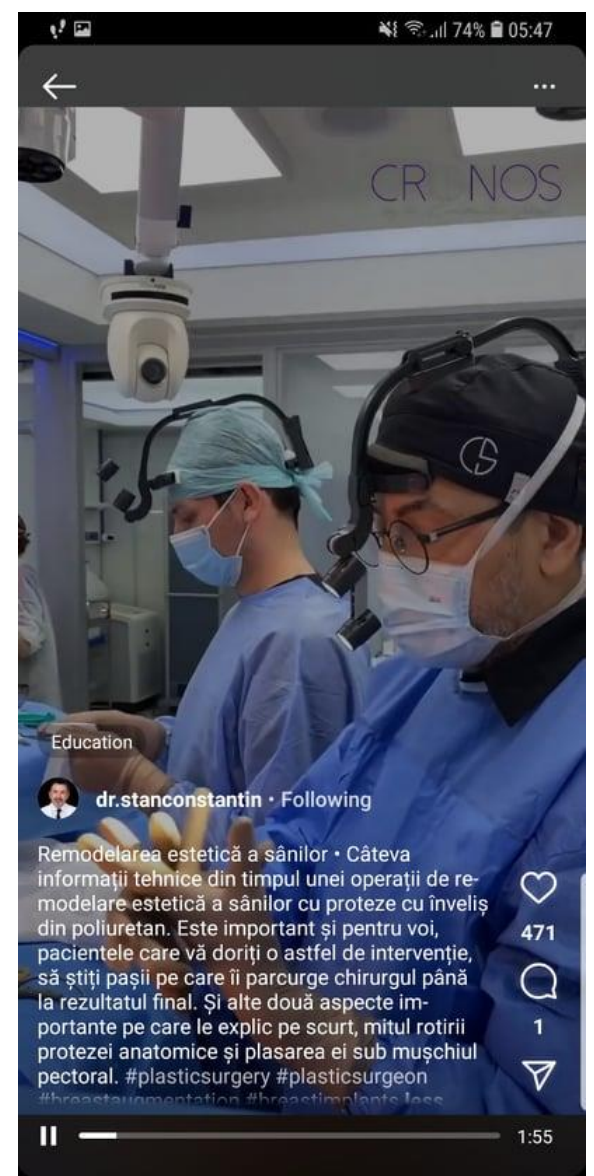

Figure 6. Video of breast surgery

Source: Ionescu (2021c).

Under the tag "education" these series of posts reconfirm the way in which surgeons present themselves as being in the medical avant-garde of progress, as directly involved in the research and development of new devices and technologies. As argued in the previous sections, such posts represent more latent modes employed by surgeons as private medical service providers to legitimate their position. Innovation is beneficial for the growth of the business, but also for the customers, therefore this legitimation trope can help respond to criticism that sees the surgeons as only following the profit motive. Doctor Stan dedicates a post on the International Day of Innovations to re-affirm this position, by declaring that he want to emphasize how "important it is for us surgeons to be involved in the development of different methods, techniques, implants, in order to offer our patients the best and the safest results on the long run (...). A surgeon's life means research, and today's technological prospects unquestionably make progress and the evolution of medicine much faster." (Stan, 2021a) 


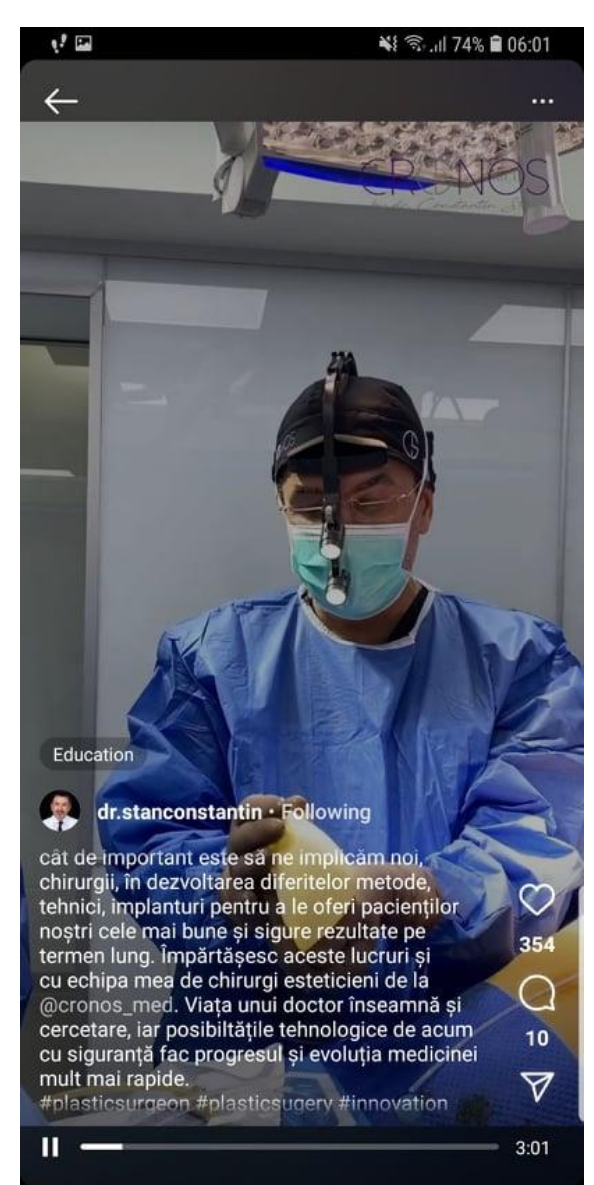

Figure 7. Video from the operating room and the importance of innovations for surgeons Source: Ionescu (2021a).

\section{CONCLUSIONS}

In lieu of conclusion, I would like to revert to the impact the legitimation repertoires of surgeons have on women's freedom to resist the pressures for body normalization. I would therefore like to draw on the work of Carole Spitzack who discusses the "impossibility of liberation through selfknowledge" (1992, p. 66). With the emergence of the informed patient-consumer, women apparently seem to draw expertise from the surgeon, and extend their freedom by being more directly informed, and involved in their bodily change. However, if we also consider the imperative of constant embodied self-development, this further responsibility they gain can also pose a higher pressure to be preoccupied with their bodies, to constantly asses them, and to perpetually choose between resisting or conforming to cosmetic bodily modification. Furthermore, as surgeons position themselves in the avant-garde of progress, and take monopoly on technical and medical innovation, resisting these cosmetic procedures can place women in the rearward of progress. It is therefore necessary to constantly take a reflexive and ethical stance towards the role of cosmetic surgeons, especially since how they position themselves involves notions that are as far reaching as from the psychological domain, to that of technical innovation and progress. Lastly, all these legitimation repertoires are subsumed to a consumer market dynamic, where the profit motive is ineluctable. 


\section{REFERENCES}

Budgeon, S. (2003). Identity as an Embodied Event. Body \& Society, 9(1), 35-55.

Cohen Shabot, S. \& Landry, C. (Ed.). (2018). Rethinking Feminist Phenomenology. Theoretical and Applied Perspectives. London and New York: Rowman \& Littlefield.

Connell, R. (2009). Gender in World Perspective. Cambridge: Polity Press.

Elfving-Hwang, J. (2013). Cosmetic Surgery and Embodying the Moral Self in South Korean Popular Makeover Culture. The Asia-Pacific Journal, 11(24), 1-11.

Fraser, S. (2003). Cosmetic Surgery, Gender and Culture. Basingstoke: Palgrave.

Gilman, S. (1998). Creating beauty to cure the soul. Race and psychology in the shaping of aesthetic surgery. Durham, London: Duke University Press.

Gilman, S. (1999). Making the Body Beautiful: A Cultural History of Aesthetic Surgery. Princeton, NJ: Princeton University Press.

Haiken, E. (1997). Venus Envy: A History of Cosmetic Surgery. Baltimore: Johns Hopkins University Press.

Heyes, C. J. (2007). Cosmetic Surgery and the Televisual Makeover. A Foucauldian feminist reading. Feminist Media Studies, 7(1), 17-32.

Ionescu, R. [dr.radu.ionescu] (2019, November 20). Photo of him and his goal as a surgeon. Retrieved on July 7, 2020, from https://www.instagram.com/p/B5FiM61luA9/? utm_medium=copy_link.

Ionescu, R. [dr.radu.ionescu] (2021, June 1). Instagram Testimonial of a satisfied patient. Retrieved on July 7, 2020, https://www.instagram.com/p/CPk2ECMlirB/?utm_medium=copy_link.

Jones, M. (2008a). Media-bodies and screen-births: Cosmetic surgery reality television. Continuum: Journal of Media \& Cultural Studies, 22(4), 515-524.

Jones, M. (2008b). Skintight: An Anatomy of Cosmetic Surgery. Oxford and New York: Berg.

Jones, M. (2009). Pygmalion's Many Faces. In In Heyes, C. J., \& Jones, M. (Eds.) Cosmetic Surgery. A feminist primer (pp. 171-190). Surrey: Ashgate Publishing Ltd.

Kaw, E. (1993). Medicalization of Racial Features: Asian American Women and Cosmetic Surgery. Medical Anthropological Quarterly, 7(1), 74-89.

Latour, B. (1993). We have never been modern. Cambridge: Harvard University Press.

Nissenbaum, A. \& Shifman, L. (2018). Meme Templates as Expressive Repertoires in a Globalizing World: A Cross-Linguistic Study. Journal of Computer-Mediated Communication, 23, 94-310.

Rose, N. (1996). Inventing Our Selves: Psychology, Power and Personhood. Cambridge and New York: Cambridge University Press.

Spitzack, C. (1992). Foucault's Political Body in Medical Practice. In Leder, D. (Ed.) The Body in Medical Thought and Practice (pp. 51-68). Dordrecht: Springer Science \& Business Media.

Stan, C. [@dr.stanconstantin] (2020, August 25). Photo of breasts, procedures, and applications used. Retrieved on August 30, 2020, from https://www.instagram.com/p/CEUlO6dJE3w/? igshid=5esr26mthffr.

Stan, C. [@dr.stanconstantin] (2021a, April 21). Video from the operating room and the importance of innovations for surgeons. Retrieved on November 7, 2021, from https://www.instagram.com/tv/CN6uVOaJrkf/?utm_medium=copy_link.

Stan, C. [@dr.stanconstantin] (2021b, May 3). Photo about the participation to a TV show where he spoke about beauty and happiness. Retrieved on November 7, 2021, from https://www.instagram.com/p/COaO9-qpDzV/?utm_medium=copy_link.

Stan, C. [@dr.stanconstantin] (2021c, July 5). Video of breast surgery. Retrieved on November 7, 2021, from https://www.instagram.com/tv/CQ9SYWXJg0y/?utm_medium=copy_link.

Stan, C. [@dr.stanconstantin] (2021d, November 3). Testimonial of satisfied customers. Retrieved on November 7, 2021, from https://www.instagram.com/p/CV0kMfuIO9I/? utm_medium=copy_link. 
Tait, S. (2007). Television And The Domestication Of Cosmetic Surgery. Feminist Media Studies, $7(2), 119-135$.

Voinea, C. (2020). The social practice of cosmetic surgery in Romania. Embodied selfdevelopment, the gaze of others, and legitimation repertoires (Doctoral Thesis). Social Work and Sociology Faculty, University of Bucharest.

Wolf, N. (2002 [1991]). The Beauty Myth: How Images of Beauty Are Used against Women. New York: HarperCollins Publishers. 